\title{
The use of hypnotics for primary insomnia in Saudi Arabia: a survey of patients' experiences and perceptions
}

Ali Dobia ( $\sim$ drali2008@yahoo.com )

General Directorate for Medical Services-Saudi Arabia https://orcid.org/0000-0001-5579-5056

Kath Ryan

University of Reading

Mohammed Abutaleb

King Fahd Central Hospital In Jazan

Ahmed BaHammam

King Saud University

Alexander Edwards

University of Reading

Research

Keywords: patients, experiences, perceptions, hypnotics, primary insomnia, Saudi Arabia

Posted Date: February 27th, 2020

DOI: https://doi.org/10.21203/rs.2.24723/v1

License: (c) (i) This work is licensed under a Creative Commons Attribution 4.0 International License. Read Full License 


\section{Abstract}

Background: This study investigated the experiences and perceptions of Saudi patients with primary insomnia.

Method: A cross-sectional design study (July 2019) using a self-administered questionnaire survey.

Results: Sixty-eight patients with primary insomnia participated (53\% male, $47 \%$ female; $60 \%$ were younger than 45 years and a majority had a university-degree education level). Of the respondents, $64.7 \%$ were dissatisfied with their knowledge of insomnia and $97 \%$ wanted more information about its treatment. Approximately $59 \%$ used prescribed sleep medicines from the first instance and only $6 \%$ were referred to a psychologist for counselling. Benzodiazepines and Z-drugs were prescribed for $16 \%$ and $19 \%$ of respondents, respectively. A majority of respondents were given antihistamines or over-the-counter herbs. While $60 \%$ of patients used medications for long periods, $87 \%$ were not involved in treatment decisions. For those on long-term use, $80 \%$ were not seen regularly by doctors and $93 \%$ were provided with no plan for medicine discontinuations. More than $60 \%$ of respondents said that sleeping pills were best for treating insomnia and $31 \%$ believed they are safe and would continue taking them. More than $45 \%$ would not prefer non-pharmacological treatments (e.g., counselling).

Conclusions: Responses to the survey indicate a lack of knowledge about primary insomnia and its treatment among Saudi patients. Prescribing hypnotics is the most common treatment, nonpharmacological treatments are seldom used, and responses indicated inappropriate and long-term use of hypnotics. Patients should be better educated about insomnia and its treatment. Physicians should consider using non-pharmacological treatments and the Saudi Ministry of Health should develop countryspecific guidelines.

\section{Background}

The prevalence of insomnia is rising, and so is the use of hypnotic drugs [1]. Benzodiazepines and Zdrugs are the most commonly prescribed medications for the management of insomnia in primary care settings [2]. There is a global lack of knowledge about the availability of Cognitive Behavioural Therapy for insomnia (CBT-I) which means that the use of hypnotic medicines is still prevalent [3]. Several studies have been conducted to determine the attitudes, perceptions, and practices of physicians with regard to the prescription of hypnotic medicines [4]. Since patients are the recipients of treatment, however, conducting regular studies with them to understand their knowledge, experiences and attitudes about insomnia and its treatments will lead to improved support and appropriate treatment [4]. A systematic review of studies conducted in Europe, the United States, Australia and New Zealand has concluded that there is a lack of knowledge and concern among patients about the long-term use and side effects of hypnotics [5].

Despite the fact that benzodiazepines and Z-drugs are associated with adverse psychomotor and cognitive effects, as well as daytime somnolence [6], many patients perceive them as safe and effective 
because they are prescribed by their doctors within a trusted medical system [5]. Even when a prescription for hypnotic medication was necessary, researchers found that physicians often prescribed them without a full discussion with the patient and without giving proper advice on the treatment $[4,7]$. There is also evidence of a lack of knowledge and awareness among patients about what to do or who to consult if experiencing side effects or what to do if drug use extends past the recommended period [5]. This situation points to the possibility that patients are not extensively involved in the treatment and decisionmaking process, resulting in suboptimal treatment outcomes and adverse drug events [8].

In Saudi Arabia, estimates of the frequency of insomnia range from 33-78\% $[9,10]$. There are no figures for the prevalence of primary insomnia, which is not related to environmental, psychiatric or medical causes [11], but it is reported to be account for $6 \%$ of all insomnia in other countries [12,13]. Findings from previous research showed that, in a tertiary hospital in Saudi Arabia, prescribing physicians did not follow international guidelines for the management of primary insomnia [14]. Some physicians suggested that Saudi patients lacked knowledge of insomnia and its treatments. One barrier to following guidelines for the treatment of primary insomnia included the fear of patients becoming dependent on hypnotics. [15]. To optimise treatment in the management of primary insomnia involving the use of hypnotics, it is necessary to develop an understanding of the knowledge, experiences, and attitudes of patients toward them. This study, therefore, aimed to explore the knowledge, experience and perception of patients about using benzodiazepines and Z-drugs to manage primary insomnia in Saudi Arabia.

\section{Methods}

\section{Online questionnaire design}

This study used a cross-sectional survey on the Survey Monkey Software platform. The questionnaire was designed based upon the scientific literature and on findings from previous studies conducted by our research group $[14,15]$. Survey questions were structured in the following six sections:

- Screening questions that allowed people with primary insomnia to complete the questionnaire and people without insomnia or other forms of insomnia to exit early.

- Patient demographics such as gender, age and educational level.

- Patients' knowledge about insomnia and its treatments.

- Patients' experiences of using prescribed hypnotics.

- Patients' perceptions about hypnotic medications.

- Patients' perceptions about non-pharmacological therapy.

\section{Validation, translation and reliability of the questionnaire}

The survey questions were prepared in English on a Microsoft Word document and then translated into the Arabic language. Three people, who were expert in the field of either sleep medicine or questionnaire methodology, validated the questionnaire. They were provided with the aim and objectives of the study and asked $\mathrm{a}$ ) if the questionnaire would address the objectives; and b) if the responses to the questions 
were likely to provide the required information $[16,17]$. In addition, they were asked to review all of the questionnaire items for readability, clarity, and comprehensiveness [16].

Two senior bilingual speakers independently translated the questionnaire from the English version into Arabic and then met to discuss differences before agreeing the Arabic translation. The Arabic draft was then translated back into English by two other bilingual speakers, who had no knowledge of the English version of the questionnaire [17]. In collaboration with the translators, the translations were reviewed by the research team to assess the back-translations for equivalence to the original English version.

Discrepancies between the two versions of translation were discussed by the research team and resolved to produce the final Arabic version [17].

The reliability of the questionnaire was checked using the test-retest method. The questionnaire was presented to 10 people, in Saudi Arabia, who were using sleep medicines. They were asked to complete the questionnaire and then one week later they were asked to complete it again. The responses were checked item-by-item to see if they were the same. All 10 people were consistent in their answers apart from one person who changed one answer from (definitely agree) to (agree) and another who added three choices instead of two to a question. These differences were not considered to make a difference to the analysis by the research team, so the questionnaire was deemed reliable.

\section{Sampling and sample size}

An appropriate number of adult patients (18 and over) in Saudi Arabia experiencing primary insomnia with unidentified causes were included in the study. Patients who have insomnia due to known physical, psychological, or environmental causes or because of the use of stimulant substances or drugs were excluded automatically by the survey.

The sample size was calculated based on the following formula [18]:

Sample size $=\frac{(\mathrm{Z} 1-\alpha / \mathrm{z}) 2 \mathrm{P}(1-\mathrm{P})}{(\mathrm{d}) 2}$ where " $\left(\mathrm{Z}_{1-\mathrm{a} / \mathrm{z}}\right)^{2}$ is a standard normal variable $($ at $5 \%$ type 1 error $(\mathrm{P}<0.05)$ it is 1.96 and at $1 \%$ type 1 error $P<0.01$ it is 2.58 )". In most studies, $P<0.05$ is considered significant, so 1.96 will be used in this study. $P$ is the estimated proportion and $d$ is the precision. As there is no current figure for primary insomnia in Saudi Arabia, the estimated prevalence of primary insomnia in the United States and Western Europe, which is $6 \%$ of individuals with chronic insomnia, was used $[12,13]$.

Therefore, it was assumed for the current study that $6 \%$ of people living with chronic insomnia in Saudi Arabia have primary insomnia. Based on the prevalence documented, a respondent group ranging from 30 to 68 was required to provide a true representation of the population of people living with primary insomnia in Saudi Arabia. A self-selecting online survey, a form of snowball sampling, was used for the study, using the Survey Monkey platform that allows Arabic text.

\section{Recruitment and data collection}

The Twitter account of one of the authors ( $A B$, the Director of the Sleep Disorders Centre in King Saud University, Saudi Arabia), which is dedicated to sleep medicine and has more than 25,000 followers, was 
used to recruit participants. To improve the response rate, the link to the Arabic version of the survey was pinned to his account on Twitter for a week. Participants were asked to forward the survey to others who they know have insomnia. Participation in the study was entirely voluntary. Instructions about how to complete the questionnaire were included on the first page of the survey. The survey was set to allow people to participate and complete the questionnaire only once. Returning the questionnaire was considered giving consent to participate. No personal information, such as names or addresses, were collected. The survey was set to be open for two weeks, however the maximum required number of participants was obtained within 5 days and the survey was then closed.

\section{Data analysis}

The data set was downloaded from the Survey Monkey server in Excel format and transferred into Stata statistical package. At first the variables were labelled and data coding was completed. Subsequently, data cleaning was performed to identify any inconsistencies in the data set. Descriptive statistics are provided for information on responses, respondent characteristics, and patients' experiences and perceptions. All relevant variables were analysed with respect to the age and sex of the respondent. A ttest was used to examine the statistical significance of apparent differences in responses to some questions by respondent gender. With a null hypothesis that there is no difference in knowledge about insomnia and its treatment between male and female genders, using unpaired t-test with a confidence limit $5 \%$ was performed; responses with statistically significant differences at this $5 \%$ level are indicated by *. For questions with Likert scales, the responses were reported as percentages. Correlations between variables were determined when applicable. To examine the statistical significance of observed dependence between certain variables, Chi squared tests were performed in contingency tables, with a null hypothesis that the responses compared were independent. Links with significance at a confidence limit of $5 \%$ are indicated by * and a confidence limit of $1 \%$ are indicated by $* *$.

\section{Ethical considerations}

Ethical approval number (17/15) was obtained from the University of Reading Research Ethics Committee and the Jazan Health Affairs, Ministry of Health in Saudi Arabia on 21 May 2019.

\section{Results}

Over five days, 217 respondents completed the online survey, which indicates considerable interest in the study. Of that total, 149 responses were excluded because the respondents had secondary insomnia. Thus, this study used a sample of 68 respondents, of whom 54 (79.4\%) reported having insomnia; the other 14 did not know or were unsure if they had primary insomnia but were all identified as people living with primary insomnia based on their responses to subsequent screening questions.

\subsection{Demographic data}

Table 1 shows the demographic characteristics of the respondents. Just above half were female gender and most of them were between 18 and 44 years old and holding university degree. 


\subsection{Knowledge about insomnia and its treatment}

When asked about their knowledge of insomnia and related problems, there were some contradictions between participants, as $82 \%$ thought that sleeping tablets are safe for short periods but $59 \%$ thought that they can be used long-term; $35 \%$ were satisfied with their knowledge but $97 \%$ wanted more information. There were also significant differences in knowledge between male and female respondents, (see Table 2).

\subsection{Experiences of using sleep medicines}

When patients were asked about their experiences using sleep medicine, around $59 \%$ reported that they had used prescribed sleep medicines and only $6 \%$ had received CBT-I. The majority of patients $(60 \%)$ had used their medications for long periods. One-quarter to one-third of the participants had tried a variety of ways to obtain sleep medicine (see Table 3 ).

Although a third of the respondents said that there was not enough time to discuss their problems with their doctor, and the vast majority (87\%) were not involved in decision-making about their treatment, most people (85\%) were told how to use their sleep medicine and were mostly compliant (70\%) with the dosage. Very few patients (6\%) were provided with a discontinuation plan and only one-fifth of long-term users were seen regularly by their doctor (see Table 3).

\subsection{Perceptions about pharmacological and non-pharmacological treatments}

When asked for their opinions about treatments, the majority of respondents did not think that long-term sleep medications are safe or did not know if they are. While $44 \%$ believed that sleeping pills are harmful and that they wanted to stop using them, $61 \%$ believed that they are the best solution for treating insomnia, and $48 \%$ often insisted on getting them. On the other hand, more than one-third of patients believed that counselling treatment offers no benefits (see Fig. 1).

To check if the patients were behaving in the way that their responses suggested, their responses were compared using cross tabulation, and Chi squared tests in contingency tables were used to assess the significance of apparent links that were identified between the variables. Our null hypothesis was that each of the two variables were completely independent. This analysis identified a number of important links with statistically significant response distribution (see Table 4). Notably, there was an increase in the number of respondents who usually persisted in getting sleeping pills, among those who tried to stop sleeping pills but could not. Likewise, patients who reported using sleeping pills for more than six months were also more likely to report that they had tried to stop sleeping pills but could not. Although there may also be a link between respondents who reported that they usually persisted in get sleeping pills and those who reported that sleeping pills can be safely used for a long time, this correlation was weaker than 
the other linked variables identified. There was, however, a link between respondents who were given advice or referred for counselling sessions and those who reported preferring non-medicine treatments. Finally, there was some indication that government hospitals were more likely to provide advice before initiating medication, while private hospitals and pharmacies were less likely do so, but this observation was not statistically significant.

\section{Discussion}

This study revealed that patients in Saudi Arabia are often prescribed hypnotics for insomnia, do not receive CBT-I as a first-line treatment and are rarely involved in the treatment decision. A majority of patients reported that they were on long-term hypnotics and were not reviewed regularly by their doctors or provided with a plan for discontinuation (Table 3). Among the patients, there was limited knowledge about insomnia and its treatments, and many were only given information about how to use hypnotic medicines when they were prescribed. Even though $44 \%$ of patients believed that hypnotics are harmful and would have liked to stop using them, they still believed that hypnotic medicines are the best solution for treating insomnia. While many patients are dependent on their medication and use different methods to get prescriptions, there is considerable resistance among them to using non-pharmacological treatments for insomnia.

One limitation of this study is the mode of sampling, which was a self-completed questionnaire that was administered via the Twitter account of a sleep medicine specialist. The bias of Twitter users who are following a sleep medicine account means that we seem to have captured a highly educated sample and missed others who either have no access to or are not interested in Twitter. The rapid response rate and high number of respondents, however, confirm that this research methodology is a powerful tool and, in spite of the limitations, represents an effective way to gain an initial understanding of patient perspectives that can subsequently be validated over a broader patient population.

The findings of this study indicate that patients usually receive sleep medication as a first-line treatment rather than non-pharmacological treatment. This finding is consistent with a previous study by our group indicating that patients in Saudi Arabia are not receiving CBT-I [14], even though it is recommended as initial therapy by many clinical guidelines [19-21] and by many experts in Saudi Arabia [22]. This might be due to Saudi physicians' lack of knowledge about non-pharmacological treatment modalities for primary insomnia or their not having the time or expertise to deliver non-pharmacological treatment to patients [15]. The current study shows that patients who had not received CBT-I reported that they believed that non-pharmacological treatment is not beneficial. This belief may have contributed to the demand for medical treatment but could conversely reflect a limitation of patient information provided at initial presentation with primary insomnia. It is possible that when patients are offered nonpharmacological intervention, they become more positive about it.

The study revealed that the majority of the participants reported limited knowledge about insomnia and its treatment, and most expressed a desire for more information about both. The study also revealed that 
most respondents believed that sleep medicines can cause dependence but can be used for long periods. This finding, though apparently contradictory, is not uncommon. As noted by Sirdifield et al. (2013), the belief that sleep medicines are not harmful may be because doctors prescribe the drugs and patients trust their doctor's professional opinion even if they prescribe them multiple times [4].

Using antihistamines and over-the-counter herbs for managing primary insomnia, long-term use of hypnotics and lack of regular reviews for patients on long-term prescriptions contradicts most of the available clinical guidelines [19-21]. These practices mirror the previous findings of a study conducted in a tertiary hospital in Saudi Arabia showing that around $44 \%$ of patients were prescribed antihistamines for primary insomnia. For long-term use, most patients had been prescribed hypnotics, but physicians did not review their patients after initiating this medication [14].

The study also revealed ineffective doctor-patient interaction among sleeping-pill users before and after being prescribed. It was noted that a majority of respondents were given sleep medicine because of the doctor's 'executive' decision and that they had been excluded from discussing their problems with the doctor. It was also noted that most long-term sleep-medicine users were not seeing their doctor regularly nor had they been provided with a plan for medicine discontinuation. These findings are consistent with a previous study showing that patients are not involved in treatment decisions [8]. This might be due to the belief of many Saudi physicians that patients lack knowledge about insomnia and its treatment [15]. What is more, physicians often find it challenging to discuss the risks or side effects of medicines with their patients [2]. This can be a source of dependence on sleep medicines. Indeed, there is a high association between long-term sleeping pill use and addiction [23, 24].

The study shows a high dependence on sleep medicines among respondents. This was evidenced by the various efforts that they had taken to access sleep medicines if the doctor had refused additional prescriptions. The study shows that respondents went to private hospitals, bought medicines from private pharmacies without prescription, went to another doctor at the same hospital, 'asked someone they know to make (wasta)' and argued with the doctor to get a prescription-all clear indications of sleeping-pill dependence and misuse [24, 25].

This study also found that a majority of respondents believed that sleep medicines are unsafe and preferred not to continue using them. Most, however, also agreed that sleep medicines are the best solution for treating insomnia. This shows that while the respondents were aware of the medicine's harmful nature, they believed that sedatives are the only option for them. The study revealed that respondents were not involved in the treatment decision or had discussed the availability of other treatments and that sleep medicines were often the first treatment given for insomnia. This could explain why the majority of respondents would like to stop their medicines. These findings are congruent with other studies that generally show that most sleep medicine users express the desire to stop using them [26]. Forty-one percent of the respondents also understood that some doctors preferred not to prescribe hypnotics, signifying an understanding of their doctor's awareness of the medicine's side effects [4]. 
The majority of respondents did not prefer non-pharmacological treatments, believing that they confer no benefits. When asked the question in different ways, the majority emphasised that they would not like to go to psychiatric hospitals for counselling therapy and most acknowledged that, if referred for counselling treatment, they would refuse. These findings support the view of many physicians that being referred to psychiatric hospitals for CBT-I carries stigma for Saudi patients and that there is a need for trained psychologists in general hospitals or specialist sleep clinics to provide the service for patients [15]. The only study conducted in Saudi Arabia to investigate stigma among patients with anxiety and depression found that the majority of patients either refused to complete the study or declined to continue when they realised that they would be asked about their mental illness [27]. This explains the extent to which Saudi patients feel stigmatised about their conditions when they are referred to psychiatric hospitals for non-pharmacological treatment.

It was noted that men were more satisfied with their knowledge of insomnia compared to women. Because the study was conducted in a country in which there has been a disparity between men and women in both access to education and the distribution of educational funds [28], this finding is plausible. A similar finding was also seen with more men than women knowing about other ways to treat insomnia. A recent study by Al-Ahmadi (2011) shows that, in general, access to information is a major challenge women in Saudi Arabia face, even including those in leadership positions [29]. Given that the sample was taken from an educated population with a majority of respondents having a university degree, possibly a result of the sampling method that relied on access to Twitter, this shows that despite the high level of education in respondents, men have better access to information than women.

This study found that women have a higher tendency than men to obtain sleep medicine from private hospitals in the first instance. We propose two reasons for this, based on the fact that $44 \%$ of those with a university degree were female. A high level of education has been correlated with high incomes [30, 31] and private hospitals are normally more expensive to access than public hospitals. Additionally, it might be easier for women to access sleep medicine in private hospitals because public hospitals are usually more accountable [32]. For this reason, public hospitals would be more reluctant to issue hypnotics in the first instance compared to private hospitals.

Global issues regarding the use of hypnotics, such as long-term use, misuse, patients not being involved in treatment decisions and patients on long-term use not being reviewed regularly by their doctors or provided with a plan for discontinuation are also common in Saudi Arabia. This study is the first of its kind to explore the knowledge, experiences and perceptions of patients concerning the use of hypnotics for treating insomnia in KSA and provides insight for future work.

\section{Conclusion}

Due to lack of information about insomnia and the different ways of treating it, Saudi patients are at higher risk of experiencing side effects with, misusing and becoming dependent on hypnotics than informed patients elsewhere. Saudi physicians could be encouraged to use non-pharmacological 
treatments as first-line therapies and educate patients about insomnia and its treatments. The Ministry of Health should develop country-specific guidelines that take account of the perspectives of prescribers and patients to optimise sleep disorder healthcare in Saudi Arabia.

\section{Abbreviations}

Cognitive Behavioural Therapy for insomnia (CBT-I)

\section{Declarations}

- Ethical approval and consent to participate: Ethical approval number (17/15) was obtained from the University of Reading Research Ethics Committee and the Jazan Health Affairs, Ministry of Health in Saudi Arabia on 21 May 2019. Returning the questionnaire was considered giving consent to participate.

- Consent to publication: not applicable

- Availability of data: The datasets generated and/or analysed during the current study are not publicly available due [because of the sensitivity of data collected from patients] but are available from the corresponding author on reasonable request.

- Competing interests: Authors have no conflict of interests and the work was not supported or funded by any drug company.

- Funding: The researcher is supported by a full-time scholarship provided by the Saudi Arabian Cultural Bureau in London.

- Authors' contributions: AD has contributed in the concepts, design, definition of intellectual content, literature search, data acquisition, data analysis, statistical analysis, manuscript preparation and manuscript editing. KR has contributed in the concepts, design, definition of intellectual content, data analysis and manuscript review. MA has contributed in the data acquisition, data analysis, statistical analysis, manuscript review. AE has contributed in the concepts, design, definition of intellectual content statistical analysis and manuscript review. AB has contributed in the concepts, data acquisition, data analysis, and manuscript review.

- Acknowledgements: not applicable

- On behalf of all the contributors I will act as guarantor and will correspond with the journal from this point onward.

- This manuscript and the essence of its contents is not previously published in part or full on any website or in a printed journal or presented at a conference/seminar.

- I declare that I have not granted any other Journal or Authority permission for reproducing prepublished information/material.

- We hereby transfer, assign, or otherwise convey all copyright ownership, including any and all rights incidental thereto, exclusively to the journal, in the event that such work is published by the journal. 


\section{References}

1. Weiß V, Heinemann S, Himmel W, Nau R, Hummers-Pradier E. The use of benzodiazepines and Zdrugs for patients with sleeping problems-A survey among hospital doctors and nurses. Deutsche medizinische Wochenschrift (1946). 2016;141 (13):e121-6.

2. Heinemann S, Weiß V, Straube K, Nau R, Grimmsmann T, Himmel W, Hummers-Pradier E. Understanding and reducing the prescription of hypnotics and sedatives at the interface of hospital care and general practice: a protocol for a mixed-methods study. BMJ open. 2016;6(8):e011908

3. Anderson KN. Insomnia and cognitive behavioural therapy-how to assess your patient and why it should be a standard part of care. J Thoracic dis. 2018;10(Suppl 1):S94-102.

4. Sirdifield C, Anthierens S, Creupelandt H, Chipchase SY, Christiaens T, Siriwardena AN. General practitioners' experiences and perceptions of benzodiazepine prescribing: systematic review and meta-synthesis. BMC family practice. 2013;14 (1):191.

5. Sirdifield C, Chipchase SY, Owen S, Siriwardena AN. A systematic review and meta-synthesis of patients' experiences and perceptions of seeking and using benzodiazepines and Z-drugs: towards safer prescribing. The Patient-Patient-Centered Outcomes Research. 2017;10(1):1-15.

6. Pollmann AS, Murphy AL, Bergman JC, Gardner DM. Deprescribing benzodiazepines and Z-drugs in community-dwelling adults: a scoping review. BMC pharmacology and toxicology. 2015;16(1):19.

7. Makoul G, Arntson P, Schofield T. Health promotion in primary care: physician-patient communication and decision making about prescription medications. Social science \& medicine. 1995;41(9):124154 .

8. Mokhar A, Kuhn S, Topp J, Dirmaier J, Härter M, Verthein U. Long-term use of benzodiazepines and Z drugs: a qualitative study of patients' and healthcare professionals' perceptions and possible levers for change. BJGP Open. 2019;28/ doi:10.3399/bjgpopen18X101626.

9. Ahmed AE, Al-Jahdali F, AlALwan A, Abuabat F, Salih SB, Al-Harbi A, Baharoon S, Khan M, Ali YZ, AlJahdali H. Prevalence of sleep duration among Saudi adults. Saudi Medical Journal. 2017;38 (3):276-283. doi:10.15537/smj.2017.3.17101.

10. Ahmed AE, Al-Jahdali H, Fatani A, Al-Rouqi K, Al-Jahdali F, Al-Harbi A, Baharoon S, Ali YZ, Khan M, Rumayyan A. The effects of age and gender on the prevalence of insomnia in a sample of the Saudi population. Ethnicity \& health. 2017;22 (3):285-294. doi:10.1080/13557858.2016.1244624.

11. J.Thorpy M. Classification of Sleep Disorders. Principles and Practice of Sleep Medicine, Fifth edn. Elsevier;2011.

12. Roth T. Insomnia: definition, prevalence, etiology, and consequences. Journal of clinical sleep medicine: JCSM: official publication of the American Academy of Sleep Medicine. 2007; 3 (5 Suppl):S7.

13. Ohayon MM. Prevalence of DSM-IV diagnostic criteria of insomnia: distinguishing insomnia related to mental disorders from sleep disorders. Journal of psychiatric research. 1997;31(3):333-346. 
14. Dobia A, Ryan K, Grant D, BaHammam A. Current clinical practice for the use of hypnotics to manage primary insomnia in adults in a tertiary hospital in Saudi Arabia: An audit study. Pharmacy. 2019; 7(1). doi:10.3390/pharmacy7010015.

15. Dobia A, Ryan K, Abutaleb M, Edwards A. Perceptions of physicians in Saudi Arabia on the use of international clinical guidelines for managing primary insomnia. PLoS ONE. 2019;14(8): e0220960. https://doi.org/10.1371/journal.pone.0220960.

16. Taherdoost $\mathrm{H}$. Validity and reliability of the research instrument; how to test the validation of a questionnaire/survey in a research. 2016;5(3):28-36.

17. Tsang S, Royse CF, Terkawi AS. Guidelines for developing, translating, and validating a questionnaire in perioperative and pain medicine. Saudi journal of anaesthesia. 2017;11(Suppl 1):S80.

18. Charan J, Biswas T. How to calculate sample size for different study designs in medical research? Indian journal of psychological medicine. 2013;35 (2):121.

19. Schutte-Rodin S, Broch L, Buysse D, Dorsey C \& Sateia M. Clinical guideline for the evaluation and management of chronic insomnia in adults. Journal of Clinical Sleep Medicine. 2008;4(5):487-504.

20. Morgan K, Kucharczyk E, \& Gregory P. Insomnia: Evidence-based approaches to assessment and management. Clin Med J. 2011;doi.org/10.7861/clinmedicine.11-3-278.

21. Qaseem A, Kansagara D, Forciea M A, Cooke M \& Denberg T D. Management of Chronic Insomnia Disorder in Adults: A Clinical Practice Guideline from the American College of Physicians. Annals of Internal Medicine. 2016;165 (2):125-33.

22. Dobia A, Ryan K, BaHammam A S \& Edwards A. Using benzodiazepines and Z-drugs for managing primary insomnia in adults in Saudi Arabia: An e-Delphi study to aid the development of clinical guidelines Sleep and Breathing. 2019; https://doi.org/10.1007/s11325-019-01794-7.

23. Dimsdale J E, Norman D, DeJardin D \& Wallace M S. The effect of opioids on sleep architecture Journal of clinical sleep medicine. 2007; 3(01):33-36.

24. Longo L P, \& Johnson B. Addiction: Part I. Benzodiazepines-side effects, abuse risk and alternatives American family physician. 2000; 61(7): 2121-28.

25. Roussin A, Bouyssi A, Pouché L, Pourcel L, \& Lapeyre-Mestre M. Misuse and dependence on nonprescription codeine analgesics or sedative $\mathrm{H} 1$ antihistamines by adults: a cross-sectional investigation in France PLOS One. 2013; 8(10):e76499.

26. King M B, Gabe J, Williams P, \& Rodrigo E K. Long term use of benzodiazepines: the views of patients The British Journal of General Practice. 1990;40(334):194.

27. Alamri, Y. Mental illness in Saudi Arabia: Stigma and acceptability.International Journal of Social Psychiatry. 2016; doi.org/10.1177/0020764016628896.

28. Hamdan A. Women and education in Saudi Arabia: Challenges and achievements. International Education Journal. 2005;6(1):42-64.

29. Al-Ahmadi H. Challenges facing women leaders in Saudi Arabia. Human Resource Development International. 2011;14(2):149-66. 
30. Bloom D E, Hartley M, \& Rosovsky H. Beyond private gain: The public benefits of higher education International handbook of higher education. Springer, Dordrecht;2007. p. 293-308.

31. Holmes C. Has the expansion of higher education led to greater economic growth? National Institute Economic Review. 2013;224 (1):R29-R47.

32. Perlstadt, H. Health Care Under the Knife: Moving Beyond Capitalism for Our Health. Social Forces. 2019; https://doi.org/10.1093/sf/soz099.

\section{Tables}

Table 1 shows the demographic characteristics of the respondents.

\begin{tabular}{|c|c|c|}
\hline Variable & $\mathbf{N}$ & $\%$ \\
\hline \multicolumn{3}{|l|}{ Gender of the respondent } \\
\hline Female & 36 & 52.9 \\
\hline Male & 32 & 47.1 \\
\hline \multicolumn{3}{|l|}{ Age of the respondent } \\
\hline Between 18 and 44 years old & 41 & 60.3 \\
\hline Between 45 and 64 years old & 26 & 38.2 \\
\hline 65 years old and over & 1 & 1.5 \\
\hline \multicolumn{3}{|c|}{ Education Level of the respondents } \\
\hline Secondary school or below & 14 & 20.6 \\
\hline University degree & 47 & 69.1 \\
\hline Masters & 4 & 5.9 \\
\hline $\mathrm{PhD}$ & 3 & 4.4 \\
\hline
\end{tabular}


Table 2: Knowledge about insomnia and its treatment (TRUE values)

\begin{tabular}{|l|l|l|l|l|}
\hline No. & Variable & $\begin{array}{l}\text { Total } \\
(\mathrm{N}=68)\end{array}$ & $\begin{array}{l}\text { Male } \\
(\mathrm{N}=32)\end{array}$ & $\begin{array}{l}\text { Female } \\
(\mathrm{N}=36)\end{array}$ \\
\cline { 3 - 5 } & & TRUE\% & TRUE\% & TRUE\% \\
\hline 1. & $\begin{array}{l}\text { I am satisfied with my knowledge about } \\
\text { insomnia and related problems * }\end{array}$ & 35.3 & 47.2 & 21.9 \\
\hline 2. & $\begin{array}{l}\text { I know that there are different ways to treat } \\
\text { insomnia other than using sleeping pills * }\end{array}$ & 64.7 & 77.8 & 50.0 \\
\hline 3. & $\begin{array}{l}\text { I would like more information about } \\
\text { insomnia and its treatment }\end{array}$ & 97.1 & 97.2 & 96.9 \\
\hline 4. & $\begin{array}{l}\text { Sleeping pills should be used when other } \\
\text { treatments (such as counselling) are } \\
\text { unsuccessful }\end{array}$ & 51.5 & 61.1 & 40.6 \\
\hline 5. & $\begin{array}{l}\text { Sleeping pills are safe but only for short } \\
\text { periods }\end{array}$ & 82.4 & 86.1 & 78.1 \\
\hline 6. & There are different types of sleeping pills & 95.6 & 97.2 & 93.8 \\
\hline 7. & $\begin{array}{l}\text { Sleeping pills might cause dependence and } \\
\text { other side effects * }\end{array}$ & 86.8 & 94.4 & 78.1 \\
\hline 8. & Sleeping pills can be used for long periods & 58.8 & 52.8 & 65.6 \\
\hline 9. & $\begin{array}{l}\text { Sleeping pills can be shared with anyone } \\
\text { (family or friends) }\end{array}$ & 19.1 & 13.9 & 25.0 \\
\hline * indicates a statistically significant difference in responses between males and \\
females with p < 0.05.
\end{tabular}

Table 3: Experience of patients regarding sleep therapeutics 
What was the first treatment provided

I was given advice for improving my sleep

I was prescribed sleep medicines 40

245.3

I was sent for a psychologist or sleep specialist for 6-8 counselling sessions

$40 \quad 58.8$

Sleeping pills currently used by the respondents

\begin{tabular}{lcc} 
Z-Drugs & 12 & 19.0 \\
\hline Benzodiazepines & 10 & 15.8 \\
\hline Antihistamines & 32 & 50.8 \\
\hline Over-the-counter herbs & 12 & 19.0 \\
\hline Others & 6 & 9.5
\end{tabular}

\section{Duration of taking sleeping pills}

Less than 6 weeks

More than 6 weeks

6

8.8

More than 6 months but less than a year

More than a year

I have never taken sleeping pills

5

When medicines are finished, where do you get them from next time?

\begin{tabular}{|c|c|c|}
\hline Go to the doctor to get another prescription & 43 & 63.2 \\
\hline Borrow the medicines from friends or family members & 3 & 4.4 \\
\hline Buy them from a private pharmacy without prescription & 22 & 32.4 \\
\hline
\end{tabular}

If your doctor refuses to give you another prescription for your medicines, what do you do? (multiple response question)

\begin{tabular}{|c|c|c|}
\hline I argue with the doctor to get the prescription & 15 & 22.1 \\
\hline I go to another doctor in the same hospital & 16 & 23.5 \\
\hline I ask someone he knows to make (Wasta) ${ }^{1}$ & 17 & 25.0 \\
\hline I go to a private hospital & 22 & 32.4 \\
\hline I borrow them from family or friends & 5 & 7.4 \\
\hline I buy them from a private pharmacy without prescription & 25 & 36.8 \\
\hline I buy them from outside Saudi Arabia, for example, from Egypt & 9 & 13.2 \\
\hline
\end{tabular}


What information did you receive when you first started using sleeping pills (multiple response)

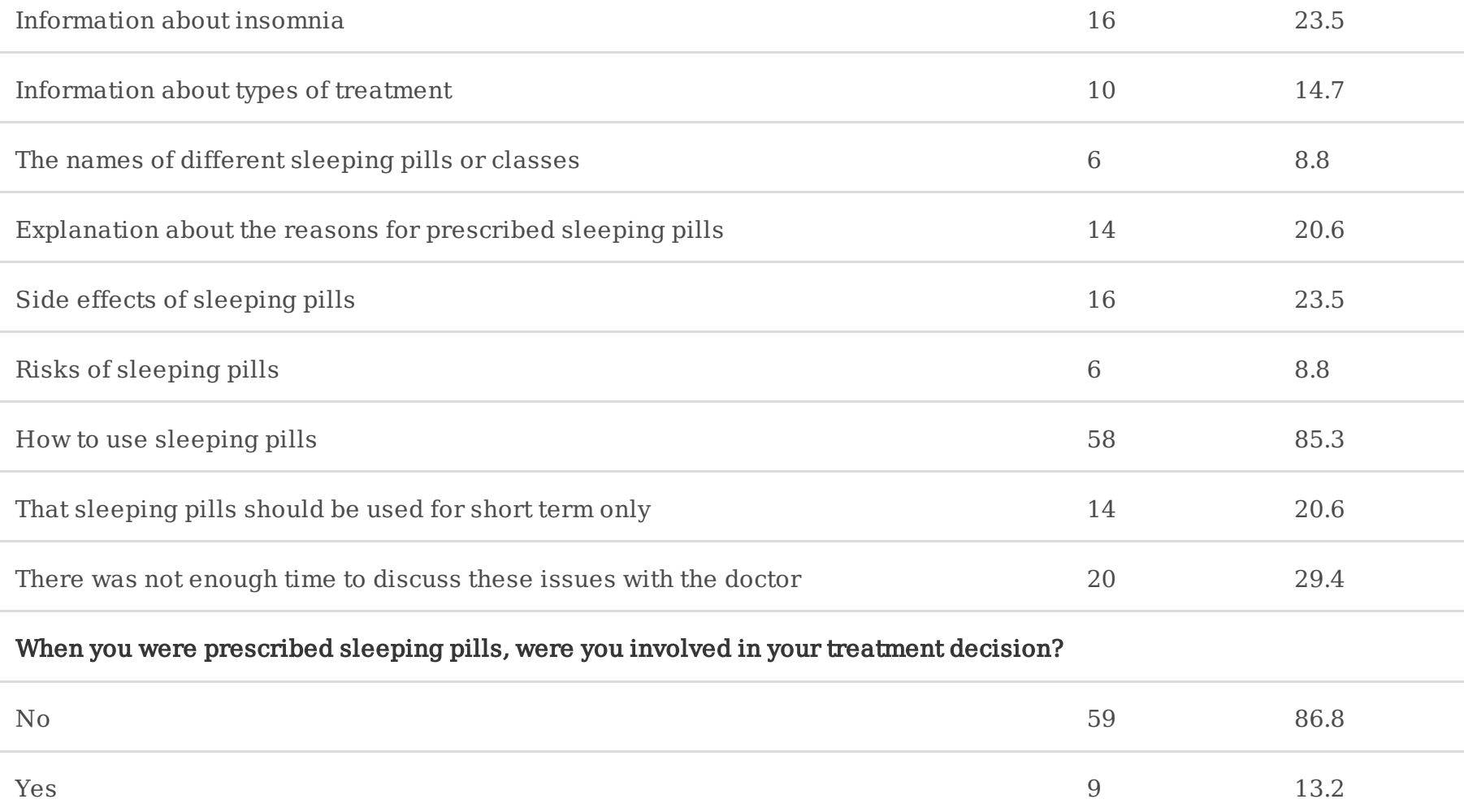

If your sleeping pills were ineffective, did you increase the dose on your own without consulting your doctor?

\begin{tabular}{|l|r} 
No & 48 \\
Yes & 20.6 \\
\hline
\end{tabular}

If you were prescribed sleeping pills for a long time, did you see your doctor regularly?

\begin{tabular}{|c|c|c|}
\hline No & 39 & 79.6 \\
\hline Yes & 10 & 20.4 \\
\hline
\end{tabular}

If you were prescribed sleeping pills for a long time, did your doctor prepare a plan for discontinuation?

\begin{tabular}{|c|c|c|}
\hline No & 45 & 93.8 \\
\hline Yes & 3 & 6.3 \\
\hline
\end{tabular}

\section{Where the respondent got their sleeping pills in the first instance}

\begin{tabular}{|c|c|c|}
\hline Governmental hospitals & 39 & 25 \\
\hline Private hospitals * & 18 & 41 \\
\hline Community pharmacy without prescription & 31 & 36 \\
\hline Family or friends & 6 & 6 \\
\hline Governmental hospitals & 39 & 25 \\
\hline
\end{tabular}


Table 4: Cross tabulation between different variables to check if the patients were behaving in the way that their responses suggested 


\begin{tabular}{|c|c|c|c|c|}
\hline \multirow[b]{2}{*}{ Usually persist to get sleeping pills } & \multicolumn{4}{|c|}{ Patients tried to stop using sleeping pills but couldn't } \\
\hline & Disagree & Neither agree or disagree & Agree & Total \\
\hline Disagree & 8 & 4 & 3 & 15 \\
\hline Neither agree or disagree & 6 & 11 & 1 & 18 \\
\hline Agree & 3 & 3 & 25 & 31 \\
\hline Total & 17 & 18 & 29 & 64 \\
\hline \multicolumn{5}{|l|}{ Chi square $=31.30473$} \\
\hline \multicolumn{5}{|l|}{ Degree of freedom $=4$} \\
\hline \multicolumn{5}{|l|}{$P$ value $=0.00001 * *$} \\
\hline & \multicolumn{4}{|c|}{ Patients tried to stop using sleeping pills but couldn't } \\
\hline Duration & Disagree & Neither agree or disagree & Agree & Total \\
\hline Less than 6 months & 8 & 10 & 1 & 19 \\
\hline More than 6 months & 9 & 7 & 28 & 44 \\
\hline Never use sleeping pills long time & 0 & 1 & 0 & 1 \\
\hline Total & 17 & 29 & 18 & 64 \\
\hline \multicolumn{5}{|l|}{ Chi square $=21.2792341$} \\
\hline \multicolumn{5}{|l|}{ Degree of freedom $=4$} \\
\hline \multicolumn{5}{|l|}{$P$ value $=0.000279 * *$} \\
\hline & \multicolumn{4}{|c|}{ Sleeping pills can be used for long time } \\
\hline Usually persist to get sleeping pills & False & True & Total & \\
\hline Disagree & 9 & 6 & 15 & \\
\hline Neither agree or disagree & 9 & 9 & 18 & \\
\hline Agree & 7 & 24 & 31 & \\
\hline Total & 25 & 39 & 64 & \\
\hline \multicolumn{5}{|l|}{ Chi square $=7.204844$} \\
\hline \multicolumn{5}{|l|}{ Degree of freedom $=2$} \\
\hline \multicolumn{5}{|l|}{$P$ value $=0.027258^{*}$} \\
\hline & \multicolumn{4}{|c|}{ Patients prefer non-medicine treatments } \\
\hline Type of treatment provided & Disagree & Neither agree or disagree & Agree & Total \\
\hline
\end{tabular}




\begin{tabular}{|lllll|}
\hline Advice & 4 & 3 & 17 & 24 \\
\hline Medicines & 19 & 13 & 8 & 40 \\
Referred for counselling sessions & 2 & 0 & 27 & 68 \\
Total & 25 & 16 & 4 & \\
Chi square $=17.506642$ & & & & \\
Degree of freedom $=4$ & & & & \\
P value $=0.001541^{* *}$ & & & & \\
\hline
\end{tabular}

\section{Figures}




\section{Perceptions about sleep medicines and counselling}

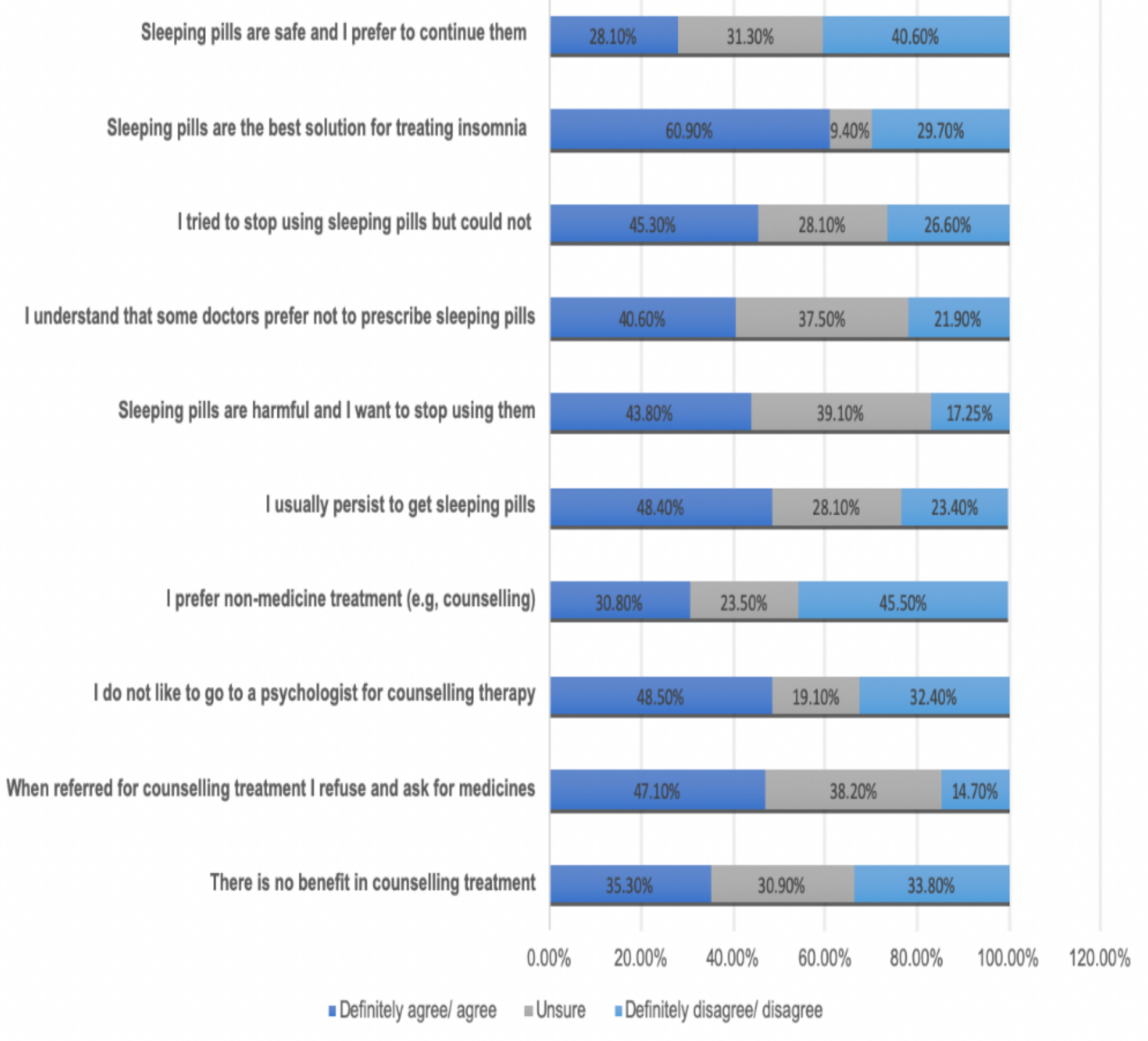

\section{Figure 1}

Perceptions about pharmacological and non-pharmacological treatments 